\title{
Regeneration, Rejuvenation, and Replacement: Turning Back the Clock on Tissue Aging
}

\author{
Thomas A. Rando ${ }^{1,2,3}$ and D. Leanne Jones $\mathrm{s}^{4,5,6}$ \\ ${ }^{1}$ Department of Neurology and Neurological Sciences; ${ }^{2}$ Glenn Center for the Biology of Aging, Stanford \\ University School of Medicine, Stanford, California 94305, USA \\ ${ }^{3}$ Neurology Service, Veterans Affairs Palo Alto Health Care System, Palo Alto, California 94304, USA \\ ${ }^{4}$ Departments of Anatomy; ${ }^{5}$ Department of Medicine, Division of Geriatrics, University of California, \\ San Francisco, California 94143, USA \\ ${ }^{6}$ Eli and Edythe Broad Center for Regeneration Medicine, University of California, San Francisco, California \\ 94143, USA \\ Correspondence: leanne.jones@ucsf.edu
}

\begin{abstract}
While some animals, such as planaria and hydra, appear to be capable of seemingly endless cycles of regeneration, most animals experience a gradual decline in fitness and ultimately die. The progressive loss of cell and tissue function, leading to senescence and death, is generally referred to as aging. Adult ("tissue") stem cells maintain tissue homeostasis and facilitate repair; however, age-related changes in stem cell function over time are major contributors to loss of organ function or disease in older individuals. Therefore, considerable effort is being invested in restoring stem cell function to counter degenerative diseases and age-related tissue dysfunction. Here, we will review strategies that could be used to restore stem cell function, including the use of environmental interventions, such as diet and exercise, heterochronic approaches, and cellular reprogramming. Maintaining optimal stem cell function and tissue homeostasis into late life will likely extend the amount of time older adults are able to be independent and lead healthy lives.
\end{abstract}

$T_{\text {hin }}^{\text {he }}$ he past 20 years have seen an exponential increase in our understanding of how aging leads to changes at the molecular and cellular levels, contributing to a decline in tissue function. Loss of cellular function over time is gradual, and changes in the "set points" that normally define homeostasis lead to a decreased ability to respond to challenges at the cellular, tissue, and organismal levels. Eventually, the decrease in re- silience leads to a decline in health and, ultimately, death.

When thinking about how aging contributes to loss of tissue function, one must consider how and when changes at the molecular or cellular level, such as mutations or a transition to senescence, begin to cumulatively alter the specialized properties and function of a tissue or organ. Rarely would all cells lose function equally or in

Editors: Kenneth D. Poss and Donald T. Fox

Additional Perspectives on Regeneration available at www.cshperspectives.org

Copyright (C) 2021 Cold Spring Harbor Laboratory Press; all rights reserved; doi: 10.1101/cshperspect.a040907

Cite this article as Cold Spring Harb Perspect Biol 2021;13:a040907 
the same way. Therefore, several key questions begin to emerge: How many cells must become dysfunctional before tissue function is disrupted? Can we do anything about it? In response to the last question, replacing non- or dysfunctional cells, particularly in the context of regenerative medicine, has gained considerable traction.

Adult ("tissue") stem cells are capable of dividing asymmetrically, with respect to cell fate, to generate both replacement stem cells (self-renewal) and progeny that differentiate along lineages with specialized functions. The remarkable ability of stem cells to self-renew and differentiate is essential to the role they play in homeostasis and repair of tissues and organs after damage or environmental insults. As such, stem cells have garnered much attention as a possible source of cells for cell-based therapies to treat injuries or degenerative diseases. However, hurdles exist, including maintenance of full potency in vivo, generation of the precise cell types in vitro needed to restore tissue function, and traditional challenges faced in the course of transplantation, such as tissue rejection. In addition, it is important that the mechanism(s) underlying loss of function be defined for each tissue of interest, as transplanted cells may not be able to sustain tissue homeostasis if the local and circulating factors that normally regulate the balance between self-renewal and differentiation are not present (Voog and Jones 2010), which could be the case in older individuals or in diseased tissues.

An alternative approach to consider, particularly for the treatment of degenerative conditions that are more prevalent in older adults, is the manipulation of endogenous stem cells. However, despite enormous proliferative potential, stem cells are also susceptible to age-related changes (Jones and Rando 2011). For example, stem cells can lose the ability to self-renew, leading to direct differentiation and depletion of the stem cell pool (Fig. 1A). In addition, the response of stem cells to signals that trigger division may be less robust, resulting in a decline in both the number of stem cells and differentiating progeny (Fig. 1B,C). Stem cells may lose "potency" and give rise to either a different number of down- stream progenitors or may be biased toward one lineage over others. Finally, stem cells may undergo programmed cell death, die by necrotic or other forms of nonapoptotic cell death, or become senescent (Fig. 1D,E; Jones and Rando 2011). Stem cell behavior is regulated by the integration of intrinsic factors and external cues (Voog and Jones 2010); therefore, it is important to note that cell-intrinsic alterations (i.e., genomic mutations), changes to the local environment known as the stem cell "niche," and fluctuations in circulating factors can all contribute to changes in stem cell function over time (Jones and Rando 2011). Here we will review interventions that could be feasible strategies for "rejuvenating" or improving the function of endogenous stem cells, focusing on stem cell responses in tissues such as blood, intestine, muscle, and brain.

\section{LINKS BETWEEN LIFE SPAN EXTENSION AND MAINTENANCE OF STEM CELL ACTIVITY}

Several paradigms discussed below are commonly considered to be life span extending or "antiaging" strategies, including changes in diet and caloric intake. Indeed, dietary restriction (DR), which is commonly defined as reduced caloric intake without malnutrition, has been shown to extend life span in all organisms in which it has been tested (Mair and Dillin 2008; Smith et al. 2020). More recently, dietary interventions that capitalize on the "fasting" states created by the normal circadian rhythms of individual organs, such as intermittent fasting (IF) or periodic fasting $(\mathrm{PF})$, have been used to generate a physiological state that resembles fasting. Recent studies have shown that maintaining a fasting physiology results in potent benefits for overall health, including reduction in visceral fat, insulin, and insulin resistance (Longo and Panda 2016). Given the close relationship between life span, health span, and tissue homeostasis, studies have probed whether some benefits of dietary interventions may be due to improvement of endogenous stem cell function (for reviews, see Jasper and Jones 2010; Mana et al. 2017). The discussion below is not meant to focus on the relationship between interventions leading to in- 

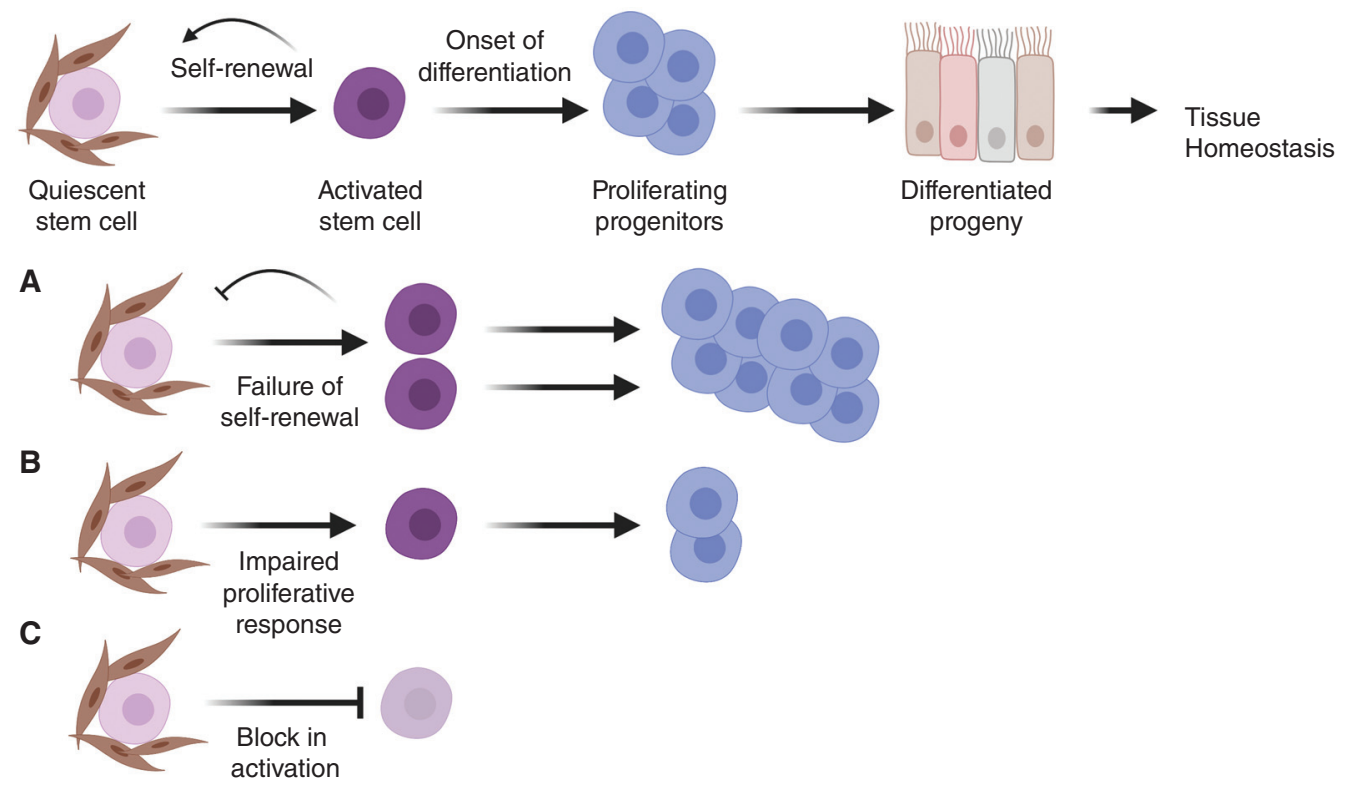

D

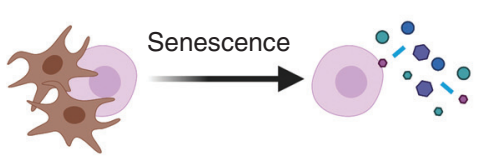

E

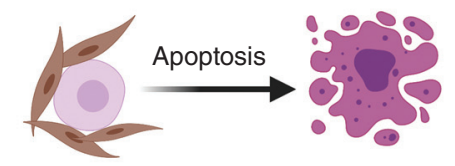

Figure 1. Effects of aging on adult stem cells. Adult stem cells reside within a niche that provides critical signals for maintenance, proliferation, and survival. Stem cells can divide to self-renew and produce progeny that will differentiate along a specific lineage. Aging can lead to a loss of tissue homeostasis when stem cells $(A)$ lose the ability to self-renew, leading to depletion of the stem cells pool, $(B)$ do not divide as often, thereby generating fewer progenitor cells, that may also be impaired, $(C)$ become unable to respond to signals from the niche that lead to "activation" and proliferation, $(D)$ become senescent and no longer divide, and/or $(E)$ die or undergo programmed cell death. Reviewed in Jones and Rando (2011). (Figure created with BioRender.com.)

creased life span and sustained tissue stem cell function. Rather, we wish to consider whether environmental interventions, such as dietary alterations, could have direct impacts on endogenous stem cells, leading to functional improvement or rejuvenation.

\section{ENVIRONMENTAL INTERVENTIONS: DIETS}

DR impacts a host of nutrient-responsive factors and signaling pathways, including the insulin and insulin-like growth factor (IGF) signaling (IIS) pathway, the mechanistic target of rapamycin (mTOR), AMP-activated protein kinase (AMPK), the cofactor nicotinamide adenine dinucleotide $\left(\mathrm{NAD}^{+}\right)$, and the family of $\mathrm{NAD}^{+}$dependent deacetylases called sirtuins. Given the different metabolic and energetic requirements of cells, teasing apart the mechanism(s) by which DR leads to an increase in life span, and, more important for this discussion, whether there is a direct impact on stem cells has been challenging (Smith et al. 2020). Yet, early studies in flies demonstrated that metabolic pathways known to regulate life span could act autonomously in adult stem cells to prolong maintenance and/or function. In the testis of Drosophila melanogaster, aging results in a loss of male germline stem cells (GSCs) over time, leading to a decrease in progenitor cells that generate mature sperm (Fig. 1A; Boyle et al. 2007). The decline in male GSCs is due to autonomous changes in the rate of stem cell proliferation, as well as a decline in signaling from the supportive 
niche (Boyle et al. 2007; Toledano et al. 2012). The IIS pathway, mutations that lead to life span extension in a range of organisms, is required for maintenance of male GSCs (McLeod et al. 2010; Smith et al. 2020). Subsequently, it was demonstrated that DR leads to life span extension, as well as maintenance of male GSCs, in flies (Mair et al. 2010). Whether IIS was required for GSC maintenance in the context of DR or whether other pathways stimulated by DR also contributed to GSC maintenance was not tested directly.

In striking contrast to a decrease in Drosophila GSCs, aging results in an increase in the proliferation of Drosophila intestinal stem cells (ISCs), which, coupled to a host of other changes, leads to a loss of intestinal homeostasis and function (Biteau et al. 2008; Choi et al. 2008; Rera et al. 2012). Studies show that DR leads to a significant improvement in intestinal homeostasis in aged flies, which was due, in part, to suppressing the increase in ISC proliferation over time (Regan et al. 2016; Akagi et al. 2018). Similar to studies described above, modulation of the IIS pathway in ISCs was also sufficient to regulate ISC behavior (Biteau et al. 2010). Reduced signaling via the insulin receptor (InR) in ISCs and progenitor cells suppressed the increase in ISC proliferation that was normally observed in aged animals. However, as with male GSCs, whether DR-mediated modulation of IIS or another pathway impacted by DR was important for maintaining intestinal homeostasis was not determined.

Mammalian ISCs are also very responsive to dietary conditions (Calibasi-Kocal et al. 2021). In the mouse, ISC regenerative capacity can be determined by the number of intestinal "organoids" (3D structures grown in vitro) generated by the ISC-containing crypts (Sato et al. 2009), as well as the ability to regenerate tissue in response to injury in vivo. DR for at least 2 weeks leads to an increase in ISC number and function, at the expense of more differentiated cells, in the mouse small intestine (Yilmaz et al. 2012). Mechanistically, this is due to reduced signaling via mTOR, a central, cellular metabolic sensor that is sensitive to growth factors and amino acids, in adjacent support cells called Paneth cells
(Yilmaz et al. 2012). DR also increased ISC regenerative capacity in response to irradiation-induced damage (Yilmaz et al. 2012). Related studies built on these findings by showing that DR-mediated activation of Sirt1 also enhanced proliferation of ISCs and promotes preservation of the "reserve" stem cell pool in an mTOR-dependent manner (Igarashi and Guarente 2016; Yousefi et al. 2018). In contrast to DR, fasting does not lead to an increase in ISC number; however, fasting interventions do promote ISC survival and proliferation and progenitor cell function in aged animals and in response to injury, such as exposure to irradiation or chemotherapeutics that cause DNA damage (Richmond et al. 2015; Tinkum et al. 2015; Mihaylova et al. 2018; Calibasi-Kocal et al. 2021).

For the hematopoietic system, dietary interventions have both beneficial and negative effects on hematopoietic stem cells (HSCs) in an aged setting. In adult, middle-aged mice, DR significantly reduced the effects of aging on HSCs. Specifically, DR supported HSC quiescence, suppressed the increase in HSC number, enhanced HSC repopulating efficiency as assayed in serial transplantation assays, and reduced the maladaptive skewing toward the myeloid lineage (Tang et al. 2016). However, despite a correction in the myeloid:lymphoid ratio, DR had a negative effect on the proliferation of lymphoid progenitors and impaired differentiation of lymphoid-biased HSCs (Tang et al. 2016). Multiple cycles of fasting also preserved total HSC numbers and enhanced proliferative capacity, while reversing the myeloid bias observed in aged mice (Cheng et al. 2014).

Taken together, these studies indicate that dietary interventions generally have a positive impact on endogenous stem cell function in a range of tissues (Fig. 2A). In particular, it appears that DR can support stem cell proliferation while fasting paradigms enhance stress resistance by providing protection against injury, and may be used to enhance the ability of stem cells to regenerate tissues in response to aging or damage (Cheng et al. 2014; Tinkum et al. 2015; Mihaylova et al. 2018). Therefore, dietary interventions could be a feasible approach to bolster stem cell function, although the overall effective- 
A
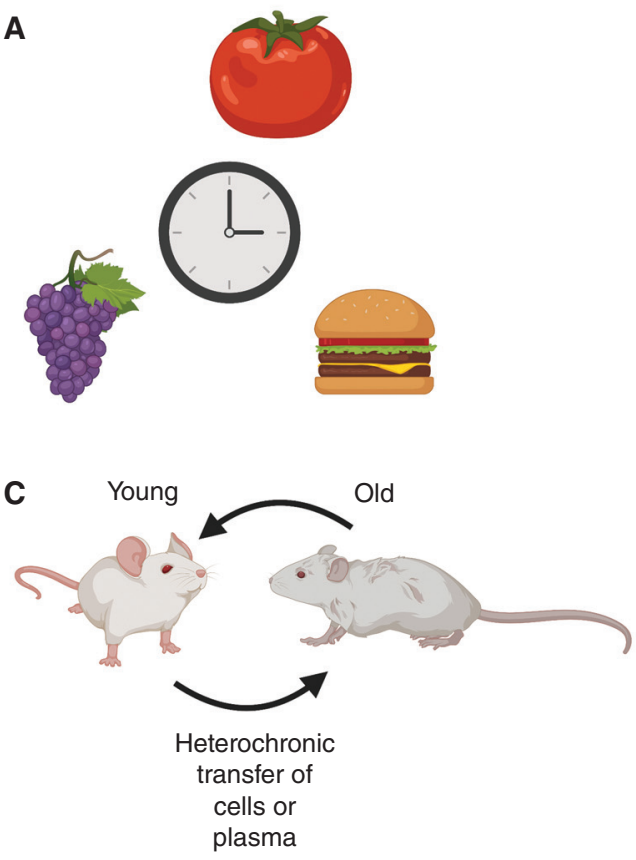

B
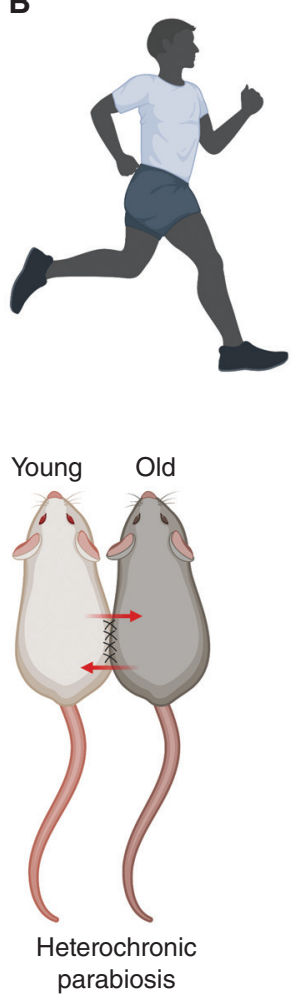

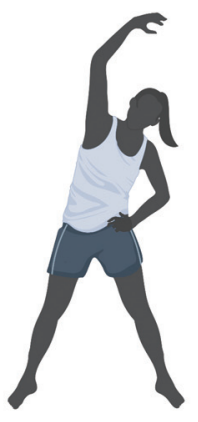

D

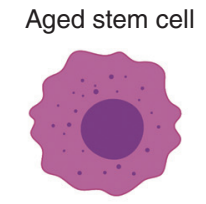

"Reprogramming"

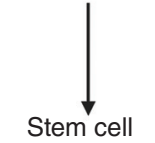

rejuvenation

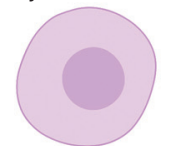

Figure 2. Approaches to rejuvenate endogenous stem cell pools. Several approaches have been used to activate or rejuvenate endogenous stem cell pools to counter age-related changes in tissue function. (A) Dietary interventions, including dietary restriction (DR) or fasting, $(B)$ nonstrenuous exercise, $(C)$ heterochronic exchange of blood, plasma, or cells, and $(D)$ reprogramming using "Yamanaka factors" to counter epigenetic changes associated with aging. (Figure created with BioRender.com.)

ness may be impacted by the total number of functional stem cells remaining. Importantly, as dietary interventions will have a systemic effect, this approach may also be one way of reversing any decline in stem cell function that is due to age-related changes in the niche.

\section{ENVIRONMENTAL INTERVENTIONS: EXERCISE}

Aging has a significant impact on the ability to learn new tasks (Gage et al. 1984; Gallagher and Rapp 1997; Smith et al. 2000), which has been associated with a decrease in neurogenesis in the dentate gyrus of the hippocampus, a brain region important for learning and memory (van Praag et al. 2005; Smith et al. 2018). Classic studies showed that exercise leads to an increase in hippocampal neurogenesis and learning in both young and aged rodents, which laid the foundation for considering exercise as an intervention that might be capable of stimulating aged neural stem cells (NSCs) to counter aging-related decline in cognition (van Praag et al. 1999a,b, 2005). Recently, factors have been identified that are enriched in the blood of young mice and healthy, aged humans that become elevated upon exercise and can confer the beneficial effects of exercise to the aged brain (Horowitz et al. 2020). After demonstrating that exercise can, indeed, reverse the decline in neurogenesis in aged (18-mo-old) mice, Horowitz et al. (2020) found that systemic administration of plasma drawn from exercised mice suppressed the age-related 
decrease in cognitive function and adult hippocampal neurogenesis. Subsequently, the group identified several factors that were increased in the blood upon exercise and demonstrated that an increase in the protein glycosylphosphatidylinositol (GPI)-specific phospholipase D1 (Gpld1), which is predominantly expressed in the liver, was sufficient to improve neurogenesis in the hippocampus, which correlated with improved cognitive abilities (Horowitz et al. 2020). Although adult neurogenesis is somewhat controversial (Paredes et al. 2018), a decline in neurogenesis has been correlated not only with a decrease in cognitive function but also with neurodegenerative diseases, such as Alzheimer's (Moreno-Jiménez et al. 2019; Tobin et al. 2019). Therefore, exercise may be an intervention to consider for stimulating neurogenesis and countering the typical, age-related decline in memory and cognition, as well as the effects of neurodegeneration.

As in the brain, exercise has been demonstrated to improve the activity of muscle stem cells (MuSCs) and accelerate muscle repair in old mice (Brett et al. 2020). When young and aged mice were allowed to run freely on a running wheel for 3 weeks, there was no increase in the total number of MuSCs; however, the ability of endogenous MuSCs to repair damage to the muscle was increased in exercised, aged mice. No difference was observed in young mice. Transplantation experiments, in which MuSCs from exercised or nonexercised aged mice were transplanted into a young host, revealed that the increase in MuSC function with voluntary exercise was due to autonomous changes, although there was also some contribution from circulating factors. Specifically, the authors found that exercise led to an increased propensity of quiescent MuSCs from aged animals to activate in response to injury, which was lost after 2 weeks of exercise cessation. Mechanistically, the enhanced exit from the resting, quiescent state was due to an increase in the G1 cyclin, cyclin D (Brett et al. 2020). An important element of these studies was the nature of the exercise voluntary wheel running. By contrast, other forms of exercise, such as forced endurance running or resistance training, lead to injury and thus directly to MuSC activation (Kurosaka et al. 2012; Begue et al. 2013; Egner et al. 2016; Abreu et al. 2017).

Although the impact of exercise on aging HSCs has not been reported, a recent study shows that voluntary running improves the ability of stromal cells within the bone marrow to support common lymphoid progenitor cells. Leptin receptor $(\mathrm{LEPR})^{+}$cells provide important growth factors for the maintenance of HSCs and early progenitors, and osteolectin is a newly identified marker of LEPR ${ }^{+}$cells that are destined to differentiate along an osteogenic lineage (Shen et al. 2021). Although a number of these $\mathrm{LEPR}^{+} /$osteolectin ${ }^{+}$cells decreases with age, Shen et al. found that mechanical stimulation, provided by voluntary exercise, was sufficient to support the maintenance of these osteogenic progenitor cells that provide a niche for lymphopoiesis. These findings suggest that exercise is not only important for maintaining the number of endogenous progenitor cells but that the benefit is amplified when the progenitors, in turn, support the activity of another stem/progenitor population (Shen et al. 2021).

Physical exercise has been generally accepted to be a safe and effective intervention to counter a broad range of age-related conditions, including obesity and cardiovascular disease (Morris et al. 2008; Booth et al. 2012). These studies suggest that endogenous stem cells could be key cellular targets that elicit such benefits (Fig. 2B). As some individuals may be incapable of exercise, identification of blood-borne factors that are increased as a consequence of exercise and can mediate the benefits, even in the absence of exercise, provide attractive therapeutic targets. However, the same factors may not activate stem cells in all tissues. Future studies are certain to identify the factors that can provide pan-tissue and tissue-specific effects, expanding our ability to rejuvenate endogenous stem cell pools to counter the agerelated decline in homeostasis.

\section{PARABIOSIS: RESTORING YOUTHFUL REGENERATION TO AGED TISSUES BY SYSTEMIC FACTORS}

The regenerative potential of most tissues declines with age, and this gradual loss is correlat- 
ed with age-related decline in stem cell functionality (Jones and Rando 2011). Much in the way that either diet or exercise can change the local and systemic milieu and influence tissue regeneration, so too can changes in the systemic circulation with age. This has been demonstrated by heterochronic studies, such as transplantation, parabiosis, and blood exchange that facilitate the exchange of tissues between animals of different ages (Fig. 2C). Early heterochronic transplantation of skeletal muscle revealed that the host environment was a greater determinant of regenerative potential of transplanted cells, whether young or old, than was the age of the cells themselves; a young host provided a more favorable environment for repair, even for old cells (Carlson and Faulkner 1989). Similarly, in heterochronic transplant studies of HSCs, a youthful host engenders a more youthful phenotype of transplanted aged cells (Ergen et al. 2012).

Building upon such evidence, heterochronic parabiosis allowed for tests of the influence of systemic factors on the regenerative potential of endogenous stem and progenitor cells. Parabiosis (literally, "living beside") is a technique of surgically connecting two organisms such that they develop a single, shared circulatory system (Conboy et al. 2013). The initial studies revealed that exposure to factors circulating in young blood led to the rejuvenation of aged muscle stem cells in a model of muscle regeneration and in aged progenitors during homeostatic turnover of liver tissue (Conboy et al. 2005; Brack et al. 2007). Subsequently, these findings were extended to reveal rejuvenation of aged neural stem cells in homeostatic neurogenesis in the hippocampus of the brain (Villeda et al. 2011). Molecular analyses reveal restoration of youthful molecular signatures in the MuSCs and liver progenitors (Conboy et al. 2005; Brack et al. 2007). In these cases, the rejuvenative effects were determined to be due to soluble factors from the young parabiont as opposed to the engraftment of circulating cells into the aged tissues. It should also be noted that not only was aged tissue repair observed to be enhanced by exposure to circulating factors in young blood, but the converse was also observed in most cases; young tissue repair was suppressed by exposure to circulating factors in old blood.

Over the next decade, multiple reports confirmed the rejuvenative potential of heterochronic parabiosis in aged tissues. There are numerous examples of benefits conferred to aged tissues, such as pancreas, heart, brain vasculature, cartilage, and kidney, in the absence of injury (Goodell and Rando 2015), perhaps by reducing the burden of senescent cells (Yousefzadeh et al. 2020). However, we will focus here on those examples in which regenerative processes were enhanced in aged tissues in the setting of heterochronic parabiosis. In the setting of demyelination, exposure to young blood of aged spinal cord that had been subjected to a demyelinating injury exhibited enhanced remyelination, and this appeared to be due largely to the influx of monocytes from the young partner (Ruckh et al. 2012). Likewise, repair of aged bone fractures was enhanced by heterochronic parabiosis, an effect that could be phenocopied by the engraftment of young hematopoietic cells into aged animals (Baht et al. 2015).

Another heterochronic technique that has been used to test for environmental influences on aged tissue regeneration has been heterochronic blood exchange. Based upon observed benefits of young plasma infusions on aged neurons (Villeda et al. 2014), heterochronic exchanges were performed to test the effects of circulating factors on stem cells and tissue regenerative potential (Rebo et al. 2016). These studies confirmed the findings of heterochronic parabiosis that young plasma enhances aged muscle regeneration and old plasma suppresses young muscle regeneration. In studies of homeostatic turnover from a single heterochronic exchange, it appeared that the suppressive effects of old plasma were more robust than the rejuvenative effects of young plasma (Rebo et al. 2016).

From these studies of systemic regulation of tissue regeneration, much interest has focused on the factors in blood that may promote or suppress regenerative responses and on the identity of the target cells on which those factors may be acting. Factors that promote regeneration and factors that inhibit regeneration have been identified in the circulation as potential mediators of 
heterochronic parabiosis or heterochronic blood exchange depending on whether they decrease or increase, respectively, with age (Ashapkin et al. 2020). Nevertheless, the complexity of the circulatory milieu, the myriad of changes that occur with age, and the cellular targets of the various proteins, steroid hormones, lipids, and metabolites that might alter regenerative responses remain only minimally explored.

Among the many questions that remain with regard to understanding how systemic factors mediate changes in tissue regenerative potential with age, is the extent to which different tissues, and even different cells within the same tissue, respond to the same or different circulating factors. For example, in the brain, numerous chemokines and cytokines that increase with age and that may each partially phenocopy the effects of heterochronic parabiosis on the young parabiont appear to act on different cell types, whether they are oligodendrocytes, endothelial cells, or neurons (Pluvinage and Wyss-Coray 2020). Furthermore, the effects may be dependent on the context of injury. The cytokine CCL11, which was shown to increase with age in the blood and cerebrospinal fluid and to suppress neurogenesis (Villeda et al. 2011), actually stimulates neural progenitor cell proliferation and migration in the setting of ischemic brain injury (Wang et al. 2017). Across tissues, there is also evidence of divergent responses. GDF11 promotes the proliferation of neural stem cells while inhibiting muscle stem cell function (Katsimpardi et al. 2014; Egerman et al. 2015), and, while its role in age-related regenerative responses remains controversial (Rodgers and Eldridge 2015), its role in promoting fibrosis is well established in many models of tissue injury and repair (Frohlich and Vinciguerra 2020). The increase of fibrosis during muscle repair after exposure to old serum was shown to be due to enhancement of Wnt signaling in the muscle stem cells, leading to a shift to a more fibrogenic fate (Brack et al. 2007). This increase in Wnt signaling was later shown to be due at least in part to the increase in the levels of circulating complement factor, C1q, and its ability to activate the Wnt pathway (Naito et al. 2012). $\beta 2$-Microglobulin was shown to increase in the plasma with age and suppress neurogenesis, and prevention of the age-related increase enhanced neurogenesis and abrogated age-related decline in cognitive function (Smith et al. 2015). However, heterochronic bone marrow transplantation was shown also to abrogate age-related decline in cognitive function without preserving neurogenesis and without reducing $\beta 2$-microglobulin levels (Das et al. 2019).

Together, these studies of heterochronic parabiosis, heterochronic blood exchange, and identification of factors that change with age in the blood point to potential therapeutic approaches to enhancing aged tissue function, some of which may be mediated by resident stem cells, in humans. Serial transfusions of young plasma are being tested in clinical trials for symptom amelioration in Alzheimer's disease (Sha et al. 2019), effects that could potentially be mediated by an enhancement of neural stem cell activity. Likewise, administration of pro-regenerative factors from young blood or the removal of profibrotic factors in old blood could promote aged tissue repair. The potential of therapies based on these fundamental observations of the regulation of stem cell regenerative potential by circulating factors is only just beginning to be explored.

\section{REPROGRAMMING: RESTORING YOUTHFUL REGENERATION TO AGED TISSUES BY STEM CELL REJUVENATION}

In addition to the multiple cell-extrinsic interventions that have been discussed that can enhance tissue regeneration with age, such as dietary manipulations or exercise, recent studies have explored the possibility that cells can be "reprogrammed" intrinsically to adopt a more youthful phenotype, leading to enhanced tissue repair in older organisms (Fig. 2D). Based on the findings from heterochronic parabiotic studies, as well as the advent of induced pluripotent stem cell (iPSC) technology, it was proposed that the restoration of aged cells to a more youthful state may occur by a process of "epigenetic rejuvenation" (Rando and Chang 2012). While this, too, applies to nonregenerative tissues, we will focus on how this has been explored in terms of aged tissue regeneration. 
Exploring the potential to apply iPSC technology to reversing epigenetic determinants of cellular age, animals were generated in which the Yamanaka reprogramming factors could be conditionally induced in adult mice (Abad et al. 2013; Ocampo et al. 2016). Whereas continuous expression of these factors led to cellular dedifferentiation and the formation of teratomas, transient and limited expression restored youthful characteristics to cells and tissues (Ocampo et al.2016). In studies of tissue regeneration, both pancreas and muscle regeneration exhibited more youthful regenerative capacities in older mice in which the cells had undergone this partial reprogramming (Ocampo et al. 2016). As the expression of the reprogramming factors was induced in all cells throughout the body, it is not possible from these experiments to attribute the improved regeneration to the rejuvenation of aged stem or progenitor cells, as opposed to immune cells or other parenchyma cells in the tissue. Nevertheless, these were the first in vivo, proof-of-principle experiments indicating that such partial reprogramming could restore youthful regenerative potential to aged tissues.

In a more translational approach, partial reprogramming of stem or progenitor cells could be achieved by the delivery of mRNA for reprogramming factors (Sarkar et al. 2020). Proof of principle was obtained for both endothelial cells and fibroblasts in vitro, showing that transient expression of the factors could restore youthful functional and molecular features of aged cells. Intriguingly, partial reprogramming of chondrocytes from aged humans with osteoarthritis was also effective in restoring youthful properties to those diseased progenitors. Finally, it was demonstrated that tissue regeneration could be enhanced in a model of aged stem cell transplantation. Muscle stem cells from aged mice were partially reprogrammed ex vivo and then transplanted into a region of injured muscle. The partial reprogramming essentially reverted the regenerative potential of the aged donor cells to that of young donor cells (Sarkar et al. 2020). This was also demonstrated using human donors of muscle stem cells in xenograft studies.

In another translational application of reprogramming of aged tissue regeneration, the deliv- ery of reprogramming factor genes by a viral vector demonstrated enhanced regeneration of an aged tissue in the form of axonal regrowth ( $\mathrm{Lu}$ et al. 2020). Using an adeno-associated viral vector, the investigators delivered only a limited set of reprogramming factors to avoid potential teratoma formation. Targeted cells in the aged retina were able to regrow their axons in response either to crush injury to the optic nerve or to optic nerve compression for experimentally induced glaucoma. Interestingly, the restoration of function was associated with changes in DNA methylation in the targeted cells, and suppressing DNA methylation abrogated the ability of reprogramming factors to restore youthful regenerative function to aged retinal cells (Lu et al. 2020).

Clearly, the future of in vivo reprogramming technology to enhance tissue regeneration will depend on effective and targeted delivery mechanisms for vectors that need to act intracellularly (such as plasmid DNA or RNA). One of the main questions that remain is the duration of exposure to the reprogramming vector necessary to achieve rejuvenation. Conversely, it remains to be determined how long the effects last after transient reprogramming. For the purposes of enhanced tissue regeneration, long-term reprogramming may be unnecessary if the effects of transient reprogramming have lasting benefits, particularly as it pertains to endogenous stem cell pools. However, as a therapeutic approach to restoring youthful function to aged stem cells in humans, these sorts of reprogramming approaches face many hurdles. First, as noted, there are intrinsic risks of generating cells with tumorigenic potential. In addition, the inability to target any kind of genetic therapy to a rare population of stem cells in a tissue is a major challenge. It may be that this kind of reprogramming technology is applied to stem cells initially in the context of ex vivo cellular reprogramming, followed by stem cell transplantation. Thus, in vivo stem cell reprogramming in humans is likely a more distant goal.

\section{CONCLUSIONS}

A major goal of regenerative medicine is to restore function to a tissue or organ that has 
become dysfunctional due to acute damage, chronic disease, or degeneration over time. $\mathrm{Al}$ though transplantation of blood and skin cells has been used for years, there are still challenges, including the fact that often the stem cells needed for robust regeneration are rare. A central focus of late has been development of techniques to generate and expand cells taken directly from a patient ex vivo for transplantation (autologous transplantation). One such approach includes generating iPSCs from the patient and then differentiating those pluripotent cells into the specific cell type needed for repair. However, as noted previously, the success of such an approach depends on many factors, including the need for reprogramming and accurately generating a tissue stem cell that is mature and maintains full potency in vitro.

Here we have discussed several alternatives to cell-based therapies that could be effective at enhancing the activity of endogenous stem cell pools, including environmental interventions such as exercise and changes to diet. Targeting endogenous stem cells may be most effective in the context of aging and degeneration, as damage and disease may result in the reduction in the number of endogenous stem cells, thereby reducing the pool of cells capable of responding to such interventions. Future studies are sure to provide more insight and technical advances to target endogenous stem cell pools to make this approach effective even for rare cells. Ultimately, when considering the best approach for regenerative medicine, a combination of cell-based therapies and environmental interventions may provide the most robust outcome. In addition, we know that aging impacts individuals in unique ways and that not all tissues "age" at the same rate (Rando and Wyss-Coray 2021). We predict that availability of molecular biomarkers of chronological and biological aging will be used to provide a personalized approach to slow or counter aging, including the efficacy of using environmental interventions to rejuvenate endogenous stem cells.

\section{ACKNOWLEDGMENTS}

The authors thank Emmanuelle Passegué for feedback on the manuscript and sincerely apol- ogize to those colleagues whose work could not be referenced directly due to space constraints. This work was supported by the National Institutes of Health (AG02892, DK105442, and GM135767 to D.L.J.) and (AG03669 and AR073248 to T.A.R.), and the Glenn Foundation for Medical Research to T.A.R.

\section{REFERENCES}

Abad M, Mosteiro L, Pantoja C, Cañamero M, Rayon T, Ors I, Graña O, Megías D, Domínguez O, Martínez D, et al. 2013. Reprogramming in vivo produces teratomas and iPS cells with totipotency features. Nature 502: 340345. doi:10.1038/nature12586

Abreu P, Mendes SV, Ceccatto VM, Hirabara SM. 2017. Satellite cell activation induced by aerobic muscle adaptation in response to endurance exercise in humans and rodents. Life Sci 170: 33-40. doi:10.1016/j .lfs.2016.11.016

Akagi K, Wilson KA, Katewa SD, Ortega M, Simons J, Hilsabeck TA, Kapuria S, Sharma A, Jasper H, Kapahi P. 2018. Dietary restriction improves intestinal cellular fitness to enhance gut barrier function and lifespan in D. melanogaster. PLoS Genet 14: e1007777. doi:10.1371/ journal.pgen.1007777

Ashapkin VV, Kutueva LI, Vanyushin BF. 2020. The effects of parabiosis on aging and age-related diseases. $A d v$ Exp Med Biol 1260: 107-122. doi:10.1007/978-3-03042667-5_5

Baht GS, Silkstone D, Vi L, Nadesan P, Amani Y, Whetstone H, Wei Q, Alman BA. 2015. Erratum: exposure to a youthful circulation rejuvenates bone repair through modulation of $\beta$-catenin. Nat Commun 6: 7761. doi:10.1038/ ncomms8761

Begue G, Douillard A, Galbes O, Rossano B, Vernus B, Candau R, Py G. 2013. Early activation of rat skeletal muscle IL-6/STAT1/STAT3 dependent gene expression in resistance exercise linked to hypertrophy. PLoS ONE 8: e57141. doi:10.1371/journal.pone.0057141

Biteau B, Hochmuth CE, Jasper H. 2008. JNK activity in somatic stem cells causes loss of tissue homeostasis in the aging Drosophila gut. Cell Stem Cell 3: 442-455. doi:10.1016/j.stem.2008.07.024

Biteau B, Karpac J, Supoyo S, Degennaro M, Lehmann R, Jasper H. 2010. Lifespan extension by preserving proliferative homeostasis in Drosophila. PLoS Genet 6: e1001159. doi:10.1371/journal.pgen.1001159

Booth FW, Roberts CK, Laye MJ. 2012. Lack of exercise is a major cause of chronic diseases. Compr Physiol 2: 11431211.

Boyle M, Wong C, Rocha M, Jones DL. 2007. Decline in selfrenewal factors contributes to aging of the stem cell niche in the Drosophila testis. Cell Stem Cell 1: 470-478. doi:10 $.1016 /$ j.stem.2007.08.002

Brack AS, Conboy MJ, Roy S, Lee M, Kuo CJ, Keller C, Rando TA. 2007. Increased Wnt signaling during aging alters muscle stem cell fate and increases fibrosis. Science $\mathbf{3 1 7}$ 807-810. doi:10.1126/science.1144090 
Brett JO, Arjona M, Ikeda M, Quarta M, de Morrée A, Egner IM, Perandini LA, Ishak HD, Goshayeshi A, Benjamin DI, et al. 2020. Exercise rejuvenates quiescent skeletal muscle stem cells in old mice through restoration of cyclin D1. Nat Metab 2: 307-317. doi:10.1038/s42255-0200190-0

Calibasi-Kocal G, Mashinchian O, Basbinar Y, Ellidokuz E, Cheng CW, Yilmaz ÖH. 2021. Nutritional control of intestinal stem cells in homeostasis and tumorigenesis. Trends Endocrinol Metab 32: 20-35. doi:10.1016/j.tem 2020.11.003

Carlson BM, Faulkner JA. 1989. Muscle transplantation between young and old rats: age of host determines recovery. Am J Physiol 256: C1262-C1266. doi:10.1152/ajpcell 1989.256.6.C1262

Cheng CW, Adams GB, Perin L, Wei M, Zhou X, Lam BS, Da Sacco S, Mirisola M, Quinn DI, Dorff TB, et al. 2014 Prolonged fasting reduces IGF-1/PKA to promote hematopoietic-stem-cell-based regeneration and reverse immunosuppression. Cell Stem Cell 14: 810-823. doi:10 .1016/j.stem.2014.04.014

Choi NH, Kim JG, Yang DJ, Kim YS, Yoo MA. 2008. Agerelated changes in Drosophila midgut are associated with PVF2, a PDGF/VEGF-like growth factor. Aging Cell 7: 318-334. doi:10.1111/j.1474-9726.2008.00380.x

Conboy IM, Conboy MJ, Wagers AJ, Girma ER, Weissman IL, Rando TA. 2005. Rejuvenation of aged progenitor cells by exposure to a young systemic environment. Nature 433: 760-764. doi: $10.1038 /$ nature 03260

Conboy MJ, Conboy IM, Rando TA. 2013. Heterochronic parabiosis: historical perspective and methodological considerations for studies of aging and longevity. Aging Cell 12: 525-530. doi:10.1111/acel.12065

Das MM, Godoy M, Chen S, Moser VA, Avalos P, Roxas KM, Dang I, Yáñez A, Zhang W, Bresee C, et al. 2019. Young bone marrow transplantation preserves learning and memory in old mice. Commun Biol 2: 73. doi:10.1038/ s42003-019-0298-5

Egerman MA, Cadena SM, Gilbert JA, Meyer A, Nelson HN, Swalley SE, Mallozzi C, Jacobi C, Jennings LL, Clay I, et al. 2015. GDF11 increases with age and inhibits skeletal muscle regeneration. Cell Metab 22: 164-174. doi:10 .1016/j.cmet.2015.05.010

Egner IM, Bruusgaard JC, Gundersen K. 2016. Satellite cell depletion prevents fiber hypertrophy in skeletal muscle. Development 143: 2898-2906. doi:10.1242/dev.134411

Ergen AV, Boles NC, Goodell MA. 2012. Rantes/Ccl5 influences hematopoietic stem cell subtypes and causes myeloid skewing. Blood 119: 2500-2509. doi:10.1182/blood2011-11-391730

Frohlich J, Vinciguerra M. 2020. Candidate rejuvenating factor GDF11 and tissue fibrosis: friend or foe? Geroscience 42: 1475-1498. doi:10.1007/s11357-020-00279-w

Gage FH, Kelly PA, Bjorklund A. 1984. Regional changes in brain glucose metabolism reflect cognitive impairments in aged rats. J Neurosci 4: 2856-2865. doi:10.1523/JNEUR OSCI.04-11-02856.1984

Gallagher M, Rapp PR. 1997. The use of animal models to study the effects of aging on cognition. Annu Rev Psychol 48: 339-370. doi:10.1146/annurev.psych.48.1.339

Goodell MA, Rando TA. 2015. Stem cells and healthy aging. Science 350: 1199-1204. doi:10.1126/science.aab3388
Horowitz AM, Fan X, Bieri G, Smith LK, Sanchez-Diaz CI, Schroer AB, Gontier G, Casaletto KB, Kramer JH, Williams KE, et al. 2020. Blood factors transfer beneficial effects of exercise on neurogenesis and cognition to the aged brain. Science 369: 167-173. doi:10.1126/science .aaw2622

Igarashi M, Guarente L. 2016. mTORC1 and SIRT1 cooperate to foster expansion of gut adult stem cells during calorie restriction. Cell 166: 436-450. doi:10.1016/j.cell .2016.05.044

Jasper H, Jones DL. 2010. Metabolic regulation of stem cell behavior and implications for aging. Cell Metab 12: 561565. doi:10.1016/j.cmet.2010.11.010

Jones DL, Rando TA. 2011. Emerging models and paradigms for stem cell ageing. Nat Cell Biol 13: 506-512. doi:10 1038/ncb0511-506

Katsimpardi L, Litterman NK, Schein PA, Miller CM, Loffredo FS, Wojtkiewicz GR, Chen JW, Lee RT, Wagers AJ, Rubin LL. 2014. Vascular and neurogenic rejuvenation of the aging mouse brain by young systemic factors. Science 344: 630-634. doi:10.1126/science.1251141

Kurosaka M, Naito H, Ogura Y, Machida S, Katamoto S. 2012. Satellite cell pool enhancement in rat plantaris muscle by endurance training depends on intensity rather than duration. Acta Physiol (Oxf) 205: 159-166. doi:10 $.1111 / \mathrm{j} .1748-1716.2011 .02381 . \mathrm{x}$

Longo VD, Panda S. 2016. Fasting, circadian rhythms, and time-restricted feeding in healthy lifespan. Cell Metab 23: 1048-1059. doi:10.1016/j.cmet.2016.06.001

Lu Y, Brommer B, Tian X, Krishnan A, Meer M, Wang C, Vera DL, Zeng Q, Yu D, Bonkowski MS, et al. 2020. Reprogramming to recover youthful epigenetic information and restore vision. Nature 588: 124-129. doi:10 .1038/s41586-020-2975-4

Mair W, Dillin A. 2008. Aging and survival: the genetics of life span extension by dietary restriction. Annu Rev Biochem 77: 727-754. doi:10.1146/annurev.biochem.77 .061206 .171059

Mair W, McLeod CJ, Wang L, Jones DL. 2010. Dietary restriction enhances germline stem cell maintenance. Aging Cell 9: 916-918. doi:10.1111/j.1474-9726.2010.00602.x

Mana MD, Kuo EY, Yilmaz OH. 2017. Dietary regulation of adult stem cells. Curr Stem Cell Rep 3: 1-8. doi:10.1007/ s40778-017-0072-x

McLeod CJ, Wang L, Wong C, Jones DL. 2010. Stem cell dynamics in response to nutrient availability. Curr Biol 20: $2100-2105$. doi:10.1016/j.cub.2010.10.038

Mihaylova MM, Cheng CW, Cao AQ, Tripathi S, Mana MD, Bauer-Rowe KE, Abu-Remaileh M, Clavain L, Erdemir A, Lewis CA, et al. 2018. Fasting activates fatty acid oxidation to enhance intestinal stem cell function during homeostasis and aging. Cell Stem Cell 22: 769-778.e4. doi:10 $.1016 /$ j.stem.2018.04.001

Moreno-Jiménez EP, Flor-García M, Terreros-Roncal J, Rábano A, Cafini F, Pallas-Bazarra N, Ávila J, Llorens-Martín M. 2019. Adult hippocampal neurogenesis is abundant in neurologically healthy subjects and drops sharply in patients with Alzheimer's disease. Nat Med 25: 554560. doi:10.1038/s41591-019-0375-9

Morris RT, Laye MJ, Lees SJ, Rector RS, Thyfault JP, Booth FW. 2008. Exercise-induced attenuation of obesity, hyperinsulinemia, and skeletal muscle lipid peroxidation 
in the OLETF rat. J Appl Physiol (1985) 104: 708-715. doi:10.1152/japplphysiol.01034.2007

Naito AT, Sumida T, Nomura S, Liu ML, Higo T, Nakagawa A, Okada K, Sakai T, Hashimoto A, Hara Y, et al. 2012. Complement $\mathrm{Clq}$ activates canonical Wnt signaling and promotes aging-related phenotypes. Cell 149: 1298-1313. doi:10.1016/j.cell.2012.03.047

Ocampo A, Reddy P, Martinez-Redondo P, Platero-Luengo A, Hatanaka F, Hishida T, Li M, Lam D, Kurita M, Beyret E, et al. 2016. In vivo amelioration of age-associated hallmarks by partial reprogramming. Cell 167: 1719-1733. e12. doi:10.1016/j.cell.2016.11.052

Paredes MF, Sorrells SF, Cebrian-Silla A, Sandoval K, Qi D, Kelley KW, James D, Mayer S, Chang J, Auguste KI, et al. 2018. Does adult neurogenesis persist in the human hippocampus? Cell Stem Cell 23: 780-781. doi:10.1016/j.stem 2018.11.006

Pluvinage JV, Wyss-Coray T. 2020. Systemic factors as mediators of brain homeostasis, ageing and neurodegeneration. Nat Rev Neurosci 21: 93-102. doi:10.1038/s41583019-0255-9

Rando TA, Chang HY. 2012. Aging, rejuvenation, and epigenetic reprogramming: resetting the aging clock. Cell 148: 46-57. doi:10.1016/j.cell.2012.01.003

Rando TA, Wyss-Coray T. 2021. Asynchronous, contagious, and digital aging. Nature Aging 1: 29-35. doi:10.1038/ s43587-020-00015-1

Rebo J, Mehdipour M, Gathwala R, Causey K, Liu Y, Conboy MJ, Conboy IM. 2016. A single heterochronic blood exchange reveals rapid inhibition of multiple tissues by old blood. Nat Commun 7: 13363. doi:10.1038/ ncomms 13363

Regan JC, Khericha M, Dobson AJ, Bolukbasi E, Rattanavirotkul N, Partridge L. 2016. Sex difference in pathology of the ageing gut mediates the greater response of female lifespan to dietary restriction. eLife 5: e10956. doi:10 $.7554 /$ eLife. 10956

Rera M, Clark RI, Walker DW. 2012. Intestinal barrier dysfunction links metabolic and inflammatory markers of aging to death in Drosophila. Proc Natl Acad Sci 109: 21528-21533. doi:10.1073/pnas.1215849110

Richmond CA, Shah MS, Deary LT, Trotier DC, Thomas H, Ambruzs DM, Jiang L, Whiles BB, Rickner HD, Montgomery RK, et al. 2015. Dormant intestinal stem cells are regulated by PTEN and nutritional status. Cell Rep 13: 2403-2411. doi:10.1016/j.celrep.2015.11.035

Rodgers BD, Eldridge JA. 2015. Reduced circulating GDF11 is unlikely responsible for age-dependent changes in mouse heart, muscle, and brain. Endocrinology 156: 3885-3888.

Ruckh JM, Zhao JW, Shadrach JL, van Wijngaarden P, Rao TN, Wagers AJ, Franklin RJ. 2012. Rejuvenation of regeneration in the aging central nervous system. Cell Stem Cell 10: 96-103. doi:10.1016/j.stem.2011.11.019

Sarkar TJ, Quarta M, Mukherjee S, Colville A, Paine P, Doan L, Tran CM, Chu CR, Horvath S, Qi LS, et al. 2020. Transient non-integrative expression of nuclear reprogramming factors promotes multifaceted amelioration of aging in human cells. Nat Commun 11: 1545. doi:10.1038/ s41467-020-15174-3

Sato T, Vries RG, Snippert HJ, van de Wetering M, Barker N, Stange DE, van Es JH, Abo A, Kujala P, Peters PJ, et al.
2009. Single Lgr5 stem cells build crypt-villus structures in vitro without a mesenchymal niche. Nature 459: 262 265. doi:10.1038/nature07935

Sha SJ, Deutsch GK, Tian L, Richardson K, Coburn M, Gaudioso JL, Marcal T, Solomon E, Boumis A, Bet A, et al. 2019. Safety, tolerability, and feasibility of young plasma infusion in the plasma for Alzheimer symptom amelioration study: a randomized clinical trial. JAMA Neurol 76: 35-40. doi:10.1001/jamaneurol.2018.3288

Shen B, Tasdogan A, Ubellacker JM, Zhang J, Nosyreva ED, Du L, Murphy MM, Hu S, Yi Y, Kara N, et al. 2021. A mechanosensitive peri-arteriolar niche for osteogenesis and lymphopoiesis. Nature 591: 438-444. doi:10.1038/ s41586-021-03298-5

Smith TD, Adams MM, Gallagher M, Morrison JH, Rapp PR. 2000. Circuit-specific alterations in hippocampal synaptophysin immunoreactivity predict spatial learning impairment in aged rats. J Neurosci 20: 6587-6593. doi:10 .1523/JNEUROSCI.20-17-06587.2000

Smith LK, He Y, Park JS, Bieri G, Snethlage CE, Lin K, Gontier G, Wabl R, Plambeck KE, Udeochu J, et al. 2015. $\beta 2$-Microglobulin is a systemic pro-aging factor that impairs cognitive function and neurogenesis. Nat Med 21: 932-937. doi:10.1038/nm.3898

Smith LK, White CW III, Villeda SA. 2018. The systemic environment: at the interface of aging and adult neurogenesis. Cell Tissue Res 371: 105-113. doi:10.1007/ s00441-017-2715-8

Smith HJ, Sharma A, Mair WB. 2020. Metabolic communication and healthy aging: where should we focus our energy? Dev Cell 54: 196-211. doi:10.1016/j.devcel.2020 .06 .011

Tang D, Tao S, Chen Z, Koliesnik IO, Calmes PG, Hoerr V, Han B, Gebert N, Zörnig M, Löffler B, et al. 2016. Dietary restriction improves repopulation but impairs lymphoid differentiation capacity of hematopoietic stem cells in early aging. $J$ Exp Med 213: 535-553. doi:10.1084/jem .20151100

Tinkum KL, Stemler KM, White LS, Loza AJ, Jeter-Jones S, Michalski BM, Kuzmicki C, Pless R, Stappenbeck TS, Piwnica-Worms D, et al. 2015. Fasting protects mice from lethal DNA damage by promoting small intestinal epithelial stem cell survival. Proc Natl Acad Sci 112: E7148-E7154. doi:10.1073/pnas.1509249112

Tobin MK, Musaraca K, Disouky A, Shetti A, Bheri A, Honer WG, Kim N, Dawe RJ, Bennett DA, Arfanakis K, et al. 2019. Human hippocampal neurogenesis persists in aged adults and Alzheimer's disease patients. Cell Stem Cell 24: 974-982.e3. doi:10.1016/j.stem.2019.05.003

Toledano H, D’Alterio C, Czech B, Levine E, Jones DL. 2012. The let-7-Imp axis regulates ageing of the Drosophila testis stem-cell niche. Nature 485: 605-610. doi:10 $.1038 /$ nature 11061

van Praag H, Christie BR, Sejnowski TJ, Gage FH. 1999a. Running enhances neurogenesis, learning, and long-term potentiation in mice. Proc Natl Acad Sci 96: 13427-13431. doi:10.1073/pnas.96.23.13427

van Praag H, Kempermann G, Gage FH. 1999b. Running increases cell proliferation and neurogenesis in the adult mouse dentate gyrus. Nat Neurosci 2: 266-270. doi:10 $.1038 / 6368$ 
van Praag H, Shubert T, Zhao C, Gage FH. 2005. Exercise enhances learning and hippocampal neurogenesis in aged mice. J Neurosci 25: 8680-8685. doi:10.1523/JNEURO SCI.1731-05.2005

Villeda SA, Luo J, Mosher KI, Zou B, Britschgi M, Bieri G Stan TM, Fainberg N, Ding Z, Eggel A, et al. 2011. The ageing systemic milieu negatively regulates neurogenesis and cognitive function. Nature 477: 90-94. doi:10.1038/ nature 10357

Villeda SA, Plambeck KE, Middeldorp J, Castellano JM, Mosher KI, Luo J, Smith LK, Bieri G, Lin K, Berdnik D, et al. 2014. Young blood reverses age-related impairments in cognitive function and synaptic plasticity in mice. Nat Med 20: 659-663. doi:10.1038/nm.3569

Voog J, Jones DL. 2010. Stem cells and the niche: a dynamic duo. Cell Stem Cell 6: 103-115. doi:10.1016/j.stem.2010 .01 .011

Wang F, Baba N, Shen Y, Yamashita T, Tsuru E, Tsuda M, Maeda N, Sagara Y. 2017. CCL11 promotes migration and proliferation of mouse neural progenitor cells. Stem Cell Res Ther 8: 26. doi:10.1186/s13287-017-0474-9

Yilmaz ÖH, Katajisto P, Lamming DW, Gültekin Y, Bauer-Rowe KE, Sengupta S, Birsoy K, Dursun A, Yilmaz VO, Selig M, et al. 2012. mTORC1 in the Paneth cell niche couples intestinal stem-cell function to calorie intake. Nature 486: 490-495. doi:10.1038/na ture11163

Yousefi M, Nakauka-Ddamba A, Berry CT, Li N, Schoenberger J, Simeonov KP, Cedeno RJ, Yu Z, Lengner CJ. 2018. Calorie restriction governs intestinal epithelial regeneration through cell-autonomous regulation of mTORC1 in reserve stem cells. Stem Cell Reports 10: 703-711. doi:10.1016/j.stemcr.2018.01.026

Yousefzadeh MJ, Wilkinson JE, Hughes B, Gadela N, Ladiges WC, Vo N, Niedernhofer LJ, Huffman DM, Robbins PD. 2020. Heterochronic parabiosis regulates the extent of cellular senescence in multiple tissues. Geroscience 42: 951-961. doi:10.1007/s11357-020-00185-1 


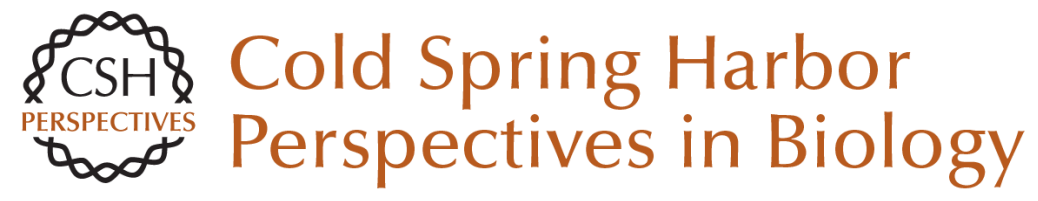

\section{Regeneration, Rejuvenation, and Replacement: Turning Back the Clock on Tissue Aging}

Thomas A. Rando and D. Leanne Jones

Cold Spring Harb Perspect Biol 2021; doi: 10.1101/cshperspect.a040907 originally published online June 29, 2021

\section{Subject Collection Regeneration}

Imaginal Disc Regeneration: Something Old, Something New

Melanie I. Worley and Iswar K. Hariharan

Somatic Lineage Reprogramming

Hannah Shelby, Tara Shelby and Marius Wernig

Genetic and Cellular Contributions to Liver

Regeneration

Roger Liang, Yu-Hsuan Lin and Hao Zhu

Hematopoietic Stem Cells and Regeneration Mitch Biermann and Tannishtha Reya

Zebrafish Fin: Complex Molecular Interactions and Cellular Mechanisms Guiding Regeneration Ivonne Sehring and Gilbert Weidinger

Comparative Biology of Vertebrate Retinal Regeneration: Restoration of Vision through Cellular Reprogramming Levi Todd and Thomas A. Reh

Pancreatic $\beta$-Cell Development and Regeneration Natanya Kerper, Sudipta Ashe and Matthias Hebrok

Positional Information and Stem Cells Combine to Result in Planarian Regeneration Peter W. Reddien

\author{
Lung Regeneration: Cells, Models, and \\ Mechanisms \\ Arvind Konkimalla, Aleksandra Tata and \\ Purushothama Rao Tata
}

The Diverse Manifestations of Regeneration and Why We Need to Study Them Vidyanand Sasidharan and Alejandro Sánchez Alvarado

All for One and One for All: Regenerating Skeletal Muscle Sajedah M. Hindi and Douglas P. Millay

Building and Maintaining the Skin Ya-Chieh Hsu and Elaine Fuchs

Positional Memory in Vertebrate Regeneration: A Century's Insights from the Salamander Limb Leo Otsuki and Elly M. Tanaka

Good Neighbors: The Niche that Fine Tunes Mammalian Intestinal Regeneration Brisa Palikuqi, Jérémie Rispal and Ophir Klein

Inducing Vertebrate Limb Regeneration: A Review of Past Advances and Future Outlook Devon Davidian and Michael Levin

Axon Regeneration: A Subcellular Extension in Multiple Dimensions

Carla C. Winter, Zhigang He and Anne Jacobi

For additional articles in this collection, see http://cshperspectives.cshlp.org/cgi/collection/

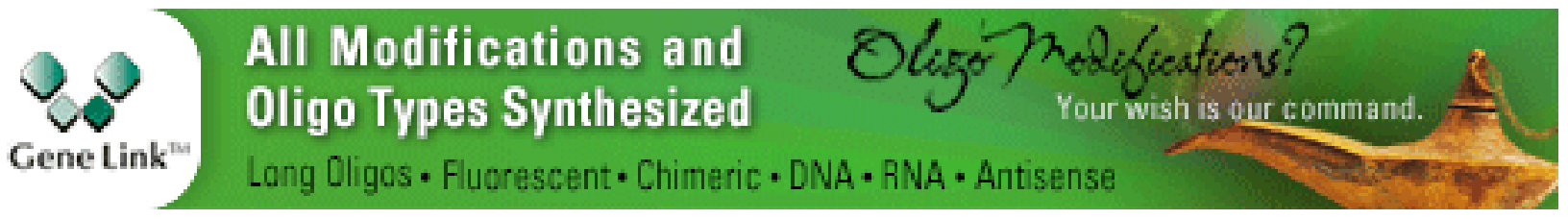


For additional articles in this collection, see http://cshperspectives.cshlp.org/cgi/collection/

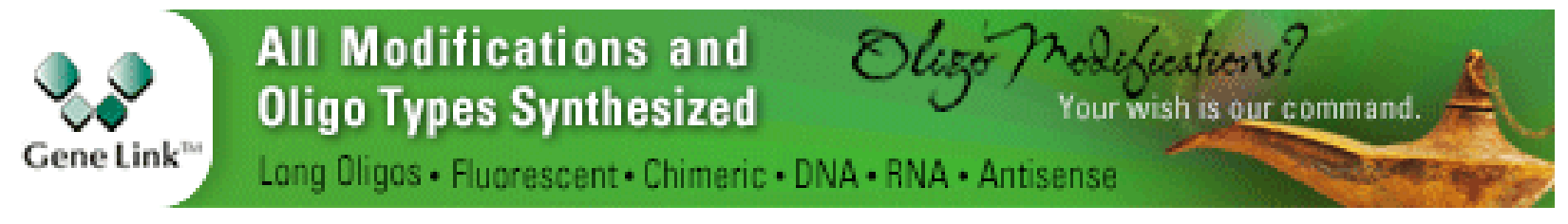

Copyright @ 2021 Cold Spring Harbor Laboratory Press; all rights reserved 